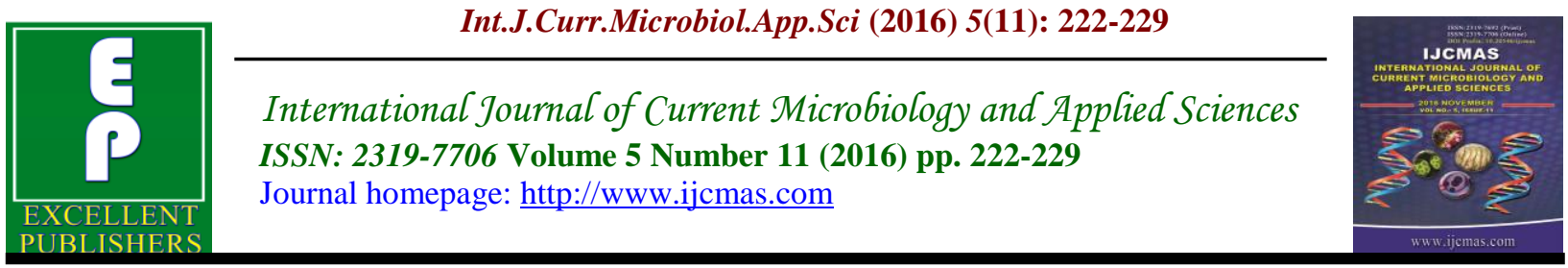

Original Research Article

http://dx.doi.org/10.20546/ijcmas.2016.511.024

\title{
Validity of Different Laboratory Methods for Diagnosis of Infectious Vaginitis: Real-Time Polymerase Chain Reaction for Detection of Trichomoniasis
}

\author{
Suzan F. Ali ${ }^{1}$, Walaa Othman Elshabrawy ${ }^{2}$, Muneera A. Alsheeha ${ }^{3}$, \\ and Ahmed Hussein ${ }^{4}$ \\ ${ }^{1}$ Departments of Medical Microbiology, ${ }^{2}$ Clinical Pathology, ${ }^{3}$ Obstetrics and Gynecology and \\ ${ }^{4}$ Center of Medical Research, College of Medicine, Qassim University, KSA \\ * Department of Clinical Pathology, Faculty of Medicine, Mansoura University, Egypt \\ *Corresponding author
}

Keywords

Bacterial, candidal and trichomonal vaginitis; wet mount; Real-time PCR.

\section{Article Info}

Accepted:

12 October 2016

Available Online:

10 November 2016
A B S T R A C T

Vaginitis syndrome is one of the most common reasons for women to seek medical attention that is mostly infectious. The aim of this study was to validate the different laboratory methods for diagnosis of infectious vaginitis and to implement the role of molecular method for detection of T. vaginalis in comparison to routine diagnostic techniques. Four vaginal swabs were collected from each woman and subjected to full microbiological laboratory studies involving direct microscopic examinations and isolation techniques. In addition, A $145 \mathrm{bp}$ long fragment of the repeated DNA target from the genome of Trichomonas vaginalis is amplified with specific primers and detected with hybridization probes using real-time PCR. All specimens were negative for Trichomonas vaginalis in wet mount preparations and twenty eight percent of cases were positive for fungal elements and bacterial agents in Gram stained smears. Forty one cases yielded positive culture, sixteen bacterial isolates, thirteen fungal isolates and no isolates of T.vaginalis were detected. Mixed bacterial and Candida isolates were found in twelve cases. Nine specimens tested positive using real-time PCR resulting in $9.4 \%$ prevalence of trichomoniasis in the women studied. From this study we can conclude that the direct microscopic examination and culture methods used shows reasonable sensitivity for detection of BV and vaginal candidiasis but not for $T$. vaginalis among the studied cases. Candidal and bacterial vaginosis can coexist. The real-time PCR was found more sensitive and rapid method for detection of $T$. vaginalis.

\section{Introduction}

Vaginitis syndrome is one of the most common reasons for women to seek medical attention and is characterized by pruritus and vaginal discharge. Bacterial vaginosis $(\mathrm{BV})$, vulvovaginal candidiasis (VVC), or trichomonal vaginitis (TV) represents over
90\% of infectious vulvovaginitis (Cartwright et al., (2013). Different groups of microorganisms are the causes of these three infectious syndromes so accurate and reliable diagnosis is necessary for appropriate treatment (Van Der Pol, 2010; Granato, 2010). 
The most frequent cause of vaginitis is the bacterial vaginosis that involves a change in vaginal ecology where the anaerobic bacteria replaces normal Lactobacillus spp. Wei et al., (2012) reported that the incidence of BV ranged from 8 to $75 \%$.More than $50 \%$ of women with BV are asymptomatic. However, serious disorders such as pelvic inflammatory disease, urinary tract infections and increased susceptibility to HIV, spontaneous and preterm birth and postpartum endometritis can be caused by BV (Hainer and Gibson, 2011).

Seventy five percent of all women have experience of an episode of VVC in their lifetimes that is a common illness due to an overgrowth of Candida species. Candida albicans accounts for $80-95 \%$ of all episodes of VVC worldwide (Guzel et al., (2011). The incidence of VVC due to nonC.albicans Candida species ranged previously from 5to $20 \%$ while, over the last two decades, the number of reported cases has increased particularly for cases of $C$. glabrata (Guzel et al., 2013).

Generally it is thought that coexistence of VVC caused by $C$. albicans and $\mathrm{BV}$ are rare, but a recent study has indicated that this view is incorrect. So, it is important to clarify the relationship between $C$. albicans and BV that helps to establish the causation, diagnosis and therapy of vaginitis (McClelland et al., 2009; Donders et al., 2011).

Trichomonas vaginalis infections are not self-limiting and produce non-ulcerative inflammation of the genital epithelium that can progress to necrosis and hemorrhage. Detection of low parasite number or defective parasites for diagnosis of trichomoniasis by using the traditional methods such as direct microscopic examination of wet mount preparations or culture based systems are both limited because of low sensitivity (Garber, 2005). However, the improvement of highly specific and sensitive diagnostic techniques based on amplification of $T$. vaginalis DNA (e.g., polymerase chain reaction (PCR) and transcription-mediated amplification (TMA) changed significantly the view on detection of trichomoniasis in such these cases (Hobbs and Seña, 2013).

The aim of this study was to validate the different laboratory methods for diagnosis of infectious vaginitis which may have synergistic pathological effects from symptomatic and asymptomatic patients and to implement the role of molecular method for detection of $T$. vaginalis in comparison to routine diagnostic techniques.

\section{Subjects and Methods}

The study was conducted on 100women patients who were referred to the gynecologic clinics from October 2012 to March 2015. Their ages ranged from 20 to 55 years. Four vaginal swabs were collected from each woman and examined as following:

First vaginal swab was immersed in a 10 ml test tube containing $2 \mathrm{ml}$ normal saline for bacterial and yeast cultures as well as Gram stained smears

Yeast cultures were performed by inoculating $50 \mu \mathrm{l}$ of liquid from swabs onto Sabouraud's dextrose agar with chloramphenicol, incubating at $37^{\circ} \mathrm{C}$ for 3 days. Also, bacterial cultures were performed aerobically and anaerobically by inoculating $50 \mu \mathrm{l}$ of liquid from swabs onto blood and chocolate agar, incubating at $37^{\mathrm{O}} \mathrm{C}$ for $16-24 \mathrm{~h}$. Further identification for isolates was done by Gram stain and fully automated Vitek 2 Compact System (bioMérieux, France). 
The remaining liquid in the tube was shaked well using vortex, centrifuged and the sediment was used for smear preparation.

Second vaginal swab was immersed in a $10 \mathrm{ml}$ test tube containing $0.5 \mathrm{ml}$ normal saline for wet mount preparation

One drop of the fluid was put on glass slide, covered and examined under the microscope. Positive result was defined as presence of one or more trichomonads with characteristic morphology and jerky motility.

Third vaginal swab was immersed in a tube containing $10 \mathrm{ml}$ of the modified Diamond culture medium for isolation of Trichomonas vaginalis

The culture tubes were incubated at $37^{\circ} \mathrm{C}$ for 72 hours then examined daily for 3-5 days by taking samples from the sediment by wet mount for detection of the Trichomonas motility.

Fourth vaginal swab was immersed in a $10 \mathrm{ml}$ test tube containing $2 \mathrm{ml}$ normal saline for PCR assay

The swab was vortexed, pressed against the tube side then removed. The tube was closed and kept at $-80^{\circ} \mathrm{C}$ for further PCR assay.

Trichomonas vaginalis DNA was extracted using the high pure PCR template preparation kit (Roche Diagnostics) following the manufacturer's recommendations.

A $145 \mathrm{bp}$ long fragment of the repeated DNA target from the genome of Trichomonas vaginalis is amplified with specific primers and detected with hybridization probes labeled with the dye LC690.Amplifications reactions were performed in a total volume of $20 \mu \mathrm{l}$ including $25 \mathrm{mM} \mathrm{MgCl} 2$ (1.6 ul), reagent mix containing primer and probe $20 \mathrm{pM}$ for each (2ul), 2 ul Light Cycler Fast Start DNA master hybridization probe buffer, 9.4ulPCR-grade water and $5 \mathrm{ul}$ of template DNA. The cycling conditions used include the following: $95^{\circ} \mathrm{C}$ for $10 \mathrm{~min}$, followed by 50 cycles of $95^{\circ} \mathrm{C}$ for $5 \mathrm{~s}, 62^{\circ} \mathrm{C}$ for $5 \mathrm{~s}$, and $72^{\circ} \mathrm{C}$ for 15 s. Data collection was performed during the annealing phase of each amplification cycle, and the fluorescent signal was monitored through the F2 channel (Riley et al., 1992; Kengne et al., 1994). The melting-curve analysis was used for identification of the PCR products derived from target DNA.

\section{Results and Discussion}

Eighteen out of 100 studied cases were asymptomatic, $55.6 \%(10 / 18)$ were positive either for culture or Gram stained smear while the remaining eight cases were negative.

Forty one cases yielded positive culture, sixteen bacterial isolates included the following species: Escherichia coli (5/41), Staphylococcus aureus (3/41), Klebsiella pneumoniae and Enterococcus faecalis (2/41 for each), Staphylococcus haemolyticus and Streptococcus agalactiae (1/41 for each) and anaerobic bacteroides (2/41). Thirteen fungal isolates speciated into: Candida albicans (9/41), Candida kefyr (2/41), Candida tropicalis and Candida famata (1/41 for each). Mixed bacterial and fungal isolates were found in twelve cases. No isolates of Trichomonas vaginalis were detected, table 1 .

Wet mount preparation showed negative results in all specimens for Trichomonas vaginalis. Gram stained smears were positive in $28 \%$ of cases for fungal elements 
such as Candida blastospores and pseudohyphae and bacterial agents.

A positive result was accepted in the Light Cycler PCR when a sample showed amplification fluorescence and a crossing point (calculated by the Light Cycler software). The melting-curve analysis was used to confirm positive results. A $145 \mathrm{bp}$ long fragment of the repeated DNA target is contained a single peak at approximately $67.5{ }^{\circ} \mathrm{C}$, The melting-curve analysis was consistent with all positive results obtained in the study (Fig. $1 \mathrm{a}$ and b). Out of 96 specimens, all (100\%) were negative by wet mount microscopy and culture, whereas nine specimens tested positive using real-time PCR resulting in $9.4 \%$ prevalence of trichomoniasis in the population studied, table 2 .

Vaginitis is one of the most common diseases mostly infectious that affect women's health, with over $50 \%$ of women have experience of at least one episode of vaginal infection in their lifetime. Infectious vaginitis is classified into three major categories of disease: bacterial vaginosis, vaginal candidiasis, and vaginal trichomoniasis. However, over $20 \%$ of infectious vaginitis cases may be mixed (Ferris et al., 1995; Lowe et al., 2009). The laboratory testing is essential for the appropriate management of patients due to clinically nonspecific nature of the vaginitis syndrome (Cartwright et al., 2013).

In the current study, all specimens were negative for Trichomonas vaginalis in wet mount preparations. Twenty eight percent of cases were positive for fungal elements and bacterial agents in Gram stained smears. So the using of Gram stain for detection of BV as well as vaginal candidiasis showed reasonable sensitivity. Establishment of the microbial etiology of infectious vaginitis can sometimes be obtained by microscopic examination of vaginal secretions, either by wet mount or Gram stain that is a reliable and inexpensive method. However, the sensitivity of the wet-mount examination for Trichomonasis only $60 \%$ to $70 \%$, and immediate evaluation of the wet mount is required for optimal results (Centers for Disease Control and Prevention, (2006). A 10-minute delay in examining the wet mount may reduce the sensitivity to $20 \%$ (Kingston et al., (2003)or even may lack sensitivity, so a negative smear result does not rule out the presence of disease.

In the present study, aerobic and anaerobic bacteria were more prevalent organisms that isolated in $16 \%$ of cases followed by Candida species isolates in $13 \%$ and mixed bacterial and Candida isolates in $12 \%$ from all studied cases. No isolates of Trichomonas vaginalis were detected.

Villaseca et al., (2015) found that the bacterial vaginosis were the most frequent infections and detected in (16.8\%) followed by vulvovaginal candidiasis in $(11.9 \%)$ and co-infections in $(6.9 \%)$ with $3 \%$ of trichomoniasis. These findings were in agreement to our results for BV and VVC.

However, Nenadić and Pavlović, (2015) reported that cervicovaginal swab cultures yielded growth of several aerobes and facultative anaerobes in $6 \%$ of patients, whereas Candida albicans was isolated in $11 \%$ of women.

In this study, zero\% of trichomoniasis was detected using the culture method and wet mount preparation. In the United States, among those who were referred to the STD clinics, the trichomoniasis was detected in $25 \%$ of cases but it was found to be higher $(38 \%)$ in certain population groups such as in African American women (World Health 
Organization, (2001). However, the other countries shows variables that ranges from $1.2 \%$ in Libya and Jordan to $3.2 \%$ in Turkey to $28.1 \%$ in Saudi Arabia (Kassemand Majoud, (2006); Selvitopu et al., (2006);
Mahafzah et al., (2008). Selection of different population groups and different isolation media used may be the reasons for the differences in results.

Table.1 Frequency of isolated microorganisms from the studied cases $(n=100)$.

\begin{tabular}{|l|c|c|}
\hline Microorganisms & Frequency & $\%$ \\
\hline Bacterial agents (No=16) & 5 & 12.2 \\
Escherichia coli & 3 & 7.3 \\
Staphylococcus aureus & 2 & 4.9 \\
Klebsiella pneumoniae & 2 & 4.9 \\
Enterococcus faecalis & 1 & 2.4 \\
Staphylococcus haemolyticus & 1 & 2.4 \\
Streptococcus agalactiae & 2 & 4.9 \\
Anaerobic Bacteroides & & \\
\hline Fungal agents (No=13) & 9 & 22 \\
Candida albicans & 1 & 4.9 \\
Candida kefyr & 1 & 2.4 \\
Candida tropicalis & 12 & 2.4 \\
Candida famata & none & 29.3 \\
\hline Mixed bacterial and fungal agents & 41 & 0.0 \\
\hline Trichomonasvaginalis & & $100.0 \%$ \\
\hline Total & & \\
\hline
\end{tabular}

Table.2 Trichomonas vaginalis - positive cases by PCR and the results of their testing by wet mount microscopy and culture

\begin{tabular}{|l|c|c|c|}
\hline Cases no & $\begin{array}{c}\text { Wet mount } \\
\text { microscopy }\end{array}$ & Culture & Real-time PCR \\
\hline 1 & $-v e$ & $-v e$ & $+v e$ \\
2 & $-v e$ & $-v e$ & $+v e$ \\
4 & $-v e$ & $-v e$ & $+v e$ \\
5 & $-v e$ & $-v e$ & $+v e$ \\
6 & $-v e$ & $-v e$ & $+v e$ \\
20 & $-v e$ & $-v e$ & $+v e$ \\
39 & $-v e$ & $-v e$ & $+v e$ \\
71 & $-v e$ & $-v e$ & $+v e$ \\
86 & $-v e$ & $-v e$ & $+v e$ \\
\hline $97,98,99,100$ & $-v e$ & $-v e$ & Not tested \\
\hline
\end{tabular}


Fig.1 Melting-curve analysis of $145 \mathrm{bp}$ long fragment of the repeated DNA target is contained a single peak at approximately $67.5^{\circ} \mathrm{C}(\mathrm{a})$ One running real-time PCR (total 32 cases) revealed positive cases with single peak and straight linear negative cases (b) Melting-curve analysis revealed single peak of one single case no 20 at $67.5^{\circ} \mathrm{C}$

(a)

File: C:LightCycler3UUsersiAdministratoriDataVast_run.ABT Program: Melting curve analysis Run By: Administrator

Run Date: Jun 10, 2015 15:05 Print Date: 2015

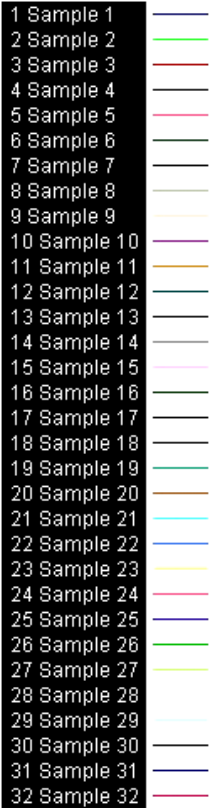

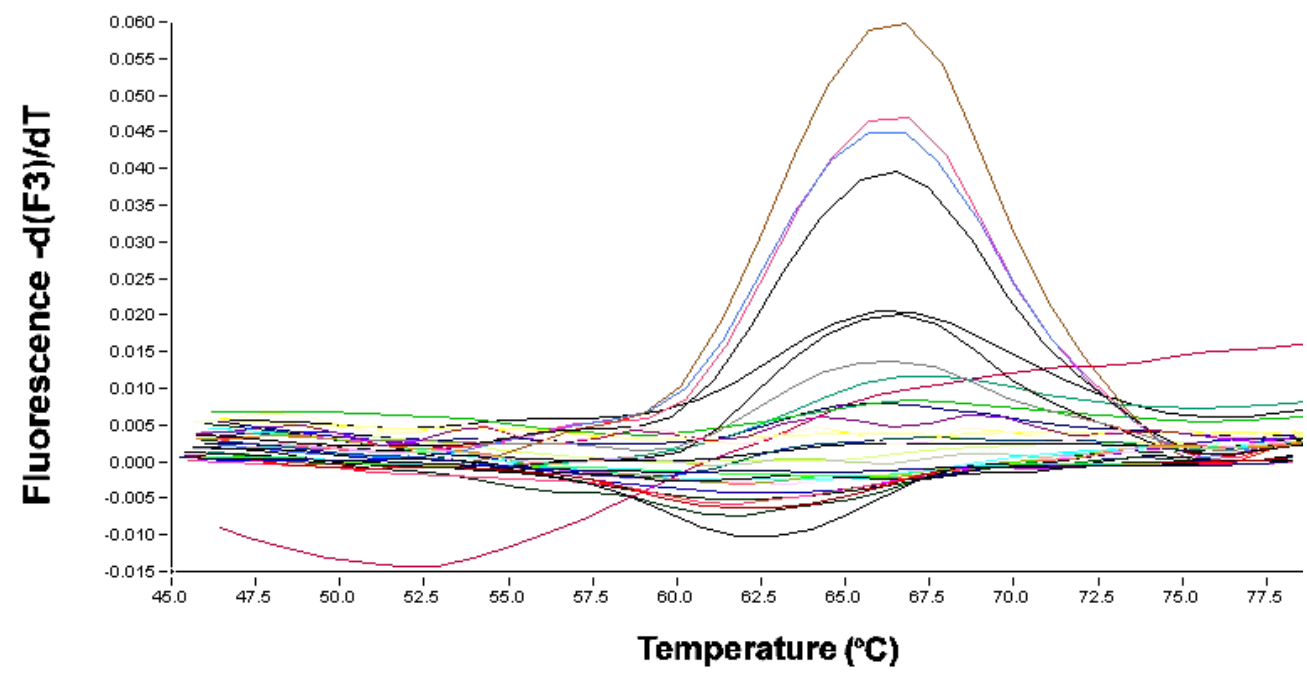

Digital Filter: Enabled

Calculation Method: Polynomial

(b)

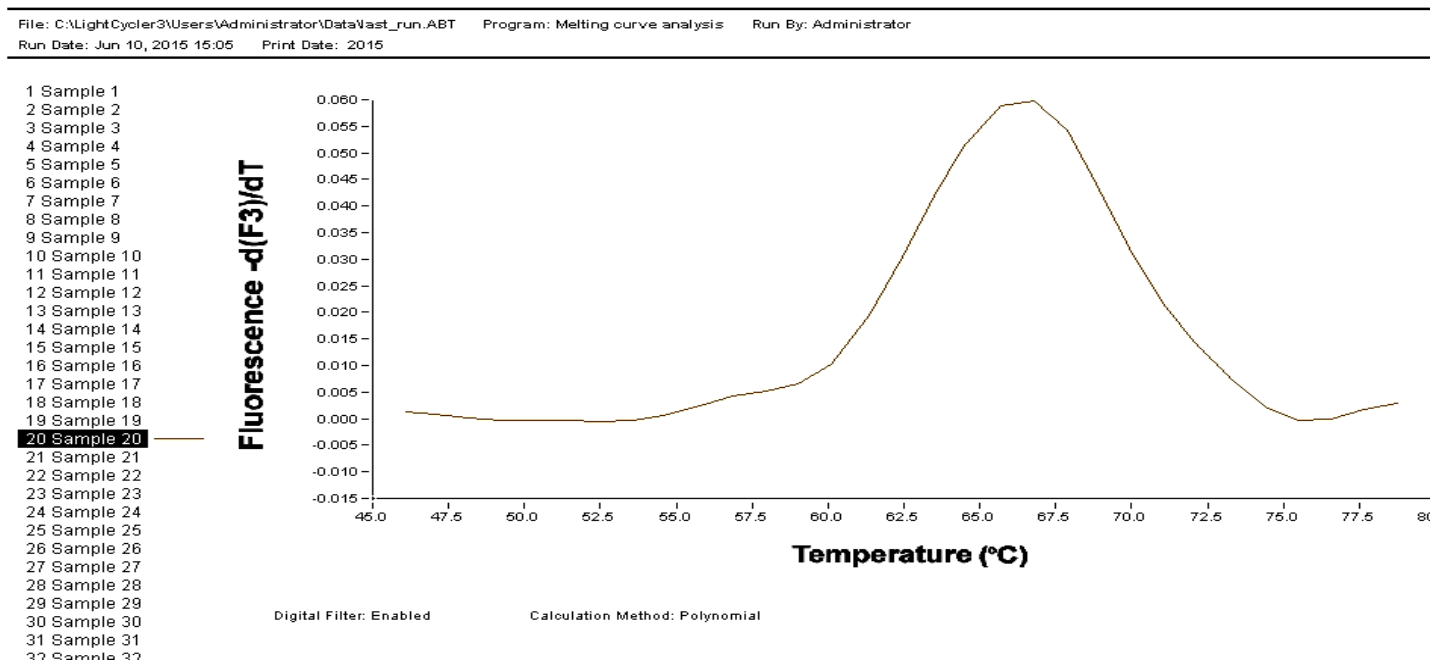

In the present study neither of the two methods wet mount preparation and culture method detected infections with $T$. vaginalis but the PCR detected reasonable rate of infection resulting in $9.4 \%$ prevalence of trichomoniasis in the studied cases. As has been shown previously, the main drawback of wet preparation and culture tests is that they leave a large portion of infections undetected. However, for the diagnosis of trichomoniasis, the limitations of direct microscopic and culture methods prompted 
the development of molecular methods for the detection of specific DNA in the vaginal samples (Wendel et al., 2002; Pillay et al., 2007; Nye et al., 2009; Patil et al., 2012; Nathan et al., 2015) and several PCR protocols have been proposed so far for the identification of T. vaginalis (Garber, 2005). The results of our study are in agreement with pervious findings which established that the sensitivity of real-time PCR is superior to that of culture and wet-mount microscopy. Furthermore, its use for diagnosing vaginitis should be considered.

In conclusion, the direct microscopic examination and culture methods used for vaginal secretions shows reasonable sensitivity for detection of $\mathrm{BV}$ and vaginal candidiasis but not for $T$. vaginalis among the studied cases. Candidal and bacterial vaginosis can coexist. The real-time PCR was found more sensitive and rapid method for detection of $T$. vaginalis. In addition, the implementation of molecular techniques may aid patient management and improve our understanding of the epidemiology of $T$. vaginalis disease by capturing accurate data.

\section{References}

Cartwright, C.P., Lembke, B.D., Ramachandran, K., Body, B.A., Nye, M.B., Rivers, C.A., et al. 2013. Comparison of nucleic acid amplification assays with BD affirm VPIII for diagnosis of vaginitis in symptomatic women. $J$. Clin. Microbiol., 51: 3694-3699.

Centers for Disease Control and Prevention. 2006. Sexually transmitted diseases treatment guidelines 2006. MMWR Recomm. Rep., 55: 1-94.

Donders, G., Bellen, G., Ausma, J., Verguts, L., Vaneldere, J., Hinoul, P., et al. 2011. The effect of antifungal treatment on the vaginal flora of women with vulvovaginal yeast infections with or without bacterial vaginosis. Eur. J. Clin.
Microbiol. Infect. Dis., 30: 59-63.

Ferris, D.G., Hendrich, J., Payne, P.M., Getts, A., Rassekh, R., Mathis, D., et al. 1995. Office laboratory diagnosis of vaginitis: clinician performed tests compared with a rapid nucleic acid hybridization test. $J$. Fam. Pract. 41: 575-581.

Garber, G.E. 2005. The laboratory diagnosis of Trichomonasvaginalis. Can. J. Infect. Dis. Med. Microbiol., 16: 35-38.

Granato, P.A. 2010. Vaginitis: clinical and laboratory aspects for diagnosis. Clin. Microbiol. Newsl., 32: 111-116.

Güzel, A.B., Aydın, M., Meral, M., Kalkancı, A., Ilkit, M. 2013. Clinical Characteristics of Turkish Women with Candida krusei Vaginitis and Antifungal Susceptibility of the C. krusei Isolates. Infect. Dis. Obstet. Gynecol., 698-736.

Guzel, A.B., Ilkit, M., Akar, T., Burgut, R., Demir, S.C. 2011. Evaluation of risk factors in patients with vulvovaginal candidiasis and the value of chromID Candida agar versus CHROMagar Candida for recovery and presumptive identification of vaginal yeast species. Med. Mycol., 49: 16-25.

Hainer, B.L., Gibson, M.V. 2011. Vaginitis: diagnosis and treatment. Am. Fam. Physician, 83: 807-815.

Hobbs, M.M., Seña, A.C. 2013. Modern diagnosis ofTrichomonasvaginalis infection. Sex Transm. Infect., 89: 434438.

Kassem, H.H., Majoud, O.A. 2006. Trichomoniasis among women with vaginal discharge in Benghazi city, Libya. J. Egypt Soc. Parasitol., 36: 1007-1016.

Kengne, P., Veas, F., Vidal, N., Rey, J.L., Cuny, G. 1994. Trichomonasvaginalis: repeated DNA target for highly sensitive and specific polymerase chain reaction diagnosis. Cell Mol. Biol., (Noisy-legrand) 40: 819-831.

Kingston, M.A., Bansal, D., Carlin, E.M. 2003. "Shelf Life" of Trichomonasvaginalis. Int. J. STD AIDS, 4: 28-29.

Lowe, N.K., Neal, J.L., Ryan-Wenger, N.A. 
2009. Accuracy of the clinical diagnosis of vaginitis compared with DNA probe laboratory standard. Obstet. Gynecol., 113: 89-95.

Mahafzah, A.M., Al-Ramahi, M.Q., Asa'd A.M., El-Khateeb, M.S. 2008. Prevalence of sexually transmitted infections among sexually active Jordanian females. Sex Transm. Dis., 35: 607-610.

McClelland, R.S., Richardson, B.A., Hassan, W.M., Graham, S.M., Kiarie, J., Baeten, J.M., et al. 2009. Prospective study of vaginal bacterial flora and other risk factors for vulvovaginal candidiasis. $J$. Infect. Dis., 199: 1883-1890.

Nathan, B., Appiah, J., Saunders, P., Heron, D., Nichols, T., Brum, R., et al. 2015. Microscopy outperformed in a comparison of five methods for detecting Trichomonasvaginalis in symptomatic women. Int. J. STD AIDS, 26: 251-256.

Nenadić, D., Pavlović, M.D. 2015. Value of bacterial culture of vaginal swabs in diagnosis of vaginal infections. Vojnosanit Pregl., 72: 523-528.

Nye, M.B., Schwebke, J.R., Body, B.A. Comparison of APTIMA Trichomonasvaginalistranscriptionmediated amplification to wet mount microscopy, culture, and polymerase chain reaction for diagnosis of trichomoniasis in men and women. Am. J. Obstet. Gynecol., 200: 188.e1-7.

Patil, M.J., Nagamoti, J.M., Metgud, S.C. 2012. Diagnosis of Trichomonasvaginalis from vaginal specimens by wet mount microscopy, in pouch TV culture system, and PCR. J. Glob. Infect. Dis., 2012;4:2225.

Pillay, A., Radebe, F., Fehler, G., Htun Y,
Ballard, R.C. 2007. Comparison of a TaqMan-based real-time polymerase chain reaction with conventional tests for the detection of Trichomonasvaginalis. Sex Transm Infect., 83: 126-129.

Riley, D.E., Roberts, M.C., Takayama, T., Krieger, J.N. 1992. Development of a polymerase chain reaction-based diagnosis of Trichomonas vaginalis. J. Clin. Microbiol., 30: 465-472.

Selvitopu, A., Ozcelik, S., Degerli, S. 2006. The incidence of Trichomonasvaginalis in vaginal specimens from gynecologic patients. Turkiye Parazitol. Derg., 30:175-177.

Van Der Pol, B. 2010. Diagnosing Vaginal Infections: It's Time to Join the 21st Century. Curr. Infect. Dis. Rep., 12: 225230.

Villaseca, R., Ovalle, A., Amaya, F., Labra, B., Escalona, N., Lizana, P., et al. 2015. Vaginal infections in a Family Health Clinic in the Metropolitan Region, Chile. MA. Rev. Chilena. Infectol., 32: 30-36.

Wei, Q., Fu, B., Liu, J., Zhang, Z., Zhao, T. 2012. Candida albicans and bacterial vaginosis can coexist on Pap smears. ActaCytol., 56: 515-519.

Wendel, K.A., Erbelding, E.J., Gaydos, C.A., Rompalo, A.M. 2002. Trichomonas aginalis polymerase chain reaction compared with standard diagnostic and therapeutic protocols for detection and treatment of vaginal trichomoniasis. Clin. Infect. Dis., 576-580.

World Health Organization. 2001. Global prevalence and incidence of selected curable sexually transmitted infections. Geneva, Switzerland: WHO.

\section{How to cite this article:}

Suzan F. Ali, Walaa Othman Elshabrawy, Muneera A. Alsheeha and Ahmed Hussein. 2016. Validity of Different Laboratory Methods for Diagnosis of Infectious Vaginitis: Real-Time Polymerase Chain Reaction for Detection of Trichomoniasis. Int.J.Curr.Microbiol.App.Sci. 5(11): 222-229. doi: http://dx.doi.org/10.20546/ijcmas.2016.511.024 